\title{
Use of 3D Drawing Software in Promoting Creativity in Preschool
}

\author{
Serkan ŞENDAĞ $\breve{G}^{*}$
}

\author{
Osman EROL $^{* *}$
}

Received: 29 November 2014

Accepted: 29 March 2015

\begin{abstract}
This study reports preliminary data on whether the use of SketchUp 3D drawing software with individualized-instructional activities in preschool can promote students' creativity. In this context, A sample of 23 preschool students at the age of 6 years old have been delivered individualized instruction for seven weeks period with a term project at the end of the program. Torrance Creative Thinking Test Figural A Form, which was developed by Torrance (1966) and adopted by Aslan (2001) for Turkish children, researchers' notes, video records, rubric for projects, and end-program interview with participants were used to collect data. Data indicated that participants showed significant improvement in the subscales of creativity test (fluency, originality, flexibility and elaboration) as well as overall creativity scores. The results of the study highlighted the efficient use of individualized instruction with a term project in teaching 3D drawing software in preschool level.
\end{abstract}

Keywords: creativity, technology, preschool education, technology education

\section{Extended Abstract}

Purpose and Significance: This study reports preliminary data on whether the use of SketchUp 3D drawing software in preschool can promote students' creativity.

Methods: 23 preschool students at the age of 6 years old have been delivered individualized instruction with a term project for seven weeks periods. Torrance Creative Thinking Test Figural-A Form, researchers' notes, video records, project assessment rubric, and end-program interview with participants were used to collect data.

Results: Data indicated that there was a significant improvement in the participants overall creativity scores as well as the subscales of the creativity test: fluency, originality, flexibility and elaboration scores. Due to the analysis of the researchers' notes and video records, it was observed that participants seemed interested in the use of the software at the very beginning of the program. They demonstrated an increasing interest and positive attitude toward software as they got used to the use of software. Data also showed that the quality of the participants' product showed improvement throughout the program. They were curious in learning how to use different features of the software, and they wanted to spend more time on the software as they become more competent. In addition, it was noted as an outstanding event that the participants who

*Corresponding Author: Assoc. Prof. Dr., Akdeniz University, Antalya, Turkey, serkansendag@akdeniz.edu.tr

** Lecturer Dr., Mehmet Akif Ersoy University, Burdur, Turkey, oerol@mehmetakif.edu.tr 
were struggled by the employment of the third dimension during instruction sessions created several 3D objects in their term projects.

Four weeks after the program ended up, due to data from one on one interviews, the participants mostly said that they kept using the software (57\%) without any external encouragement. They also said that they mostly sketched houses, kites, trains, and cars as objects, horses, and butterflies as animals, and flowers as plants. The evaluation of the student projects revealed that the participants' projects reached a high level in fluency and flexibility.

Discussion and Conclusions: In this study, findings indicated that preschool students improved their creativity skills with a significant improvement in all subscales of the creativity test: fluency, originality, flexibility and elaboration scores throughout the course on Google SketchUp software. It appeared that the course on the use of Google SketchUp can help preschool students improve their creativity. This result supports earlier studies revealing the positif significant effect of use of certain software in instruction (Karakaya ve Demirkan, 2015; Liveri, Zhou, Chen ve Lu, 2014) and use of SketchUp with high school stundents on creativity. The individualized instruction with a term project could have been also efficient in promoting creativity at preschool level. This result also supports suggestions on the use of individualized learning environments to promote creativity (Schargel ve Smink, 2001). Thus, it can be concluded that employing use of 3D software in individualized learning environments can promote 6 years old children' creativity. However, further experimental research with a control group is needed to be done to elaborate the effect found in this study.

Results indicated that 6 years old preschool students were curious about and interested in the use of SketchUp software, and their willingness increased as they got used to use the software, and explored the new features of it. Results also showed that most of the preschool students (57\%) kept using the software without external encouragement after the program ended up. High level curiosity, and motivation had always been associated with creativity (İnan, 2005; San, 1996; Yaşar, 2002).. It can be concluded that the motivating and encouraging feature of these types of 3D drawing software could be facilitated in the acquisition of creativity and higher order thinking skills.

Results also indicated that preschool students who were struggled by the employment of the third dimension during teaching and learning activities created 3D objects in their term projects. It can be concluded that 3D drawing software can be used in concept acquisition. The assessment of the students' projects revealed that the participants' projects reached a high level in fluency and flexibility. The strategies used in this study can be efficiently employed in supporting creativity skills of the preschool students, however, additional creative strategies such as taboo words and concepts, random input, etc. which were not included in the current study can be used to better foster the authenticity of the student projects. 


\title{
Okul Öncesi Dönemde Yaratıcılığı Desteklemede 3D Çizim Yazılımlarının Kullanılması
}

\author{
Serkan ŞENDAĞ $\breve{G}^{*} \quad$ Osman EROL ${ }^{* *}$
}

Makale Gönderme Tarihi: 29 Kasım 2014

Makale Kabul Tarihi: 29 Mart 2015

\begin{abstract}
ÖZET: $\mathrm{Bu}$ araştırmanın amacı bireyselleştirilmiş bir öğrenme ortamında işe koşulan üç boyutlu (3D) çizim programlarından SketchUp yazılımının okul öncesi çocukların yaratıcılığını desteklemede kullanımı konusunda ön bilgi sağlamaktır. Bu bağlamda, 23 okul öncesi altı yaş grubu çocuklara yedi hafta süren bireyselleştirilmiş SketchUp eğitimi verilmiş ve hemen ardından çocuklarla serbest proje çalışması gerçekleştirilmiştir. Araştırmada verilerin toplanması için Torrance (1966) tarafindan geliştirilen ve Aslan (2001) tarafından Türk çocuklarına uyarlaması yapılan Torrance Yaratıcı Düşünme Testi Şekilsel A Formu, araştırmacı notları ve video kayıtları kullanılmış, araştırmaya katılan çocuklar ile görüşme yapılmış ve projeleri değerlendirmek üzere üç dereceli puanlama anahtarı kullanılmıştır. Araştırma sonunda araştırmaya katılan çocukların uygulama öncesi yaratıcılık puanları ile akıcılık, orijinallik, esneklik ve ayrıntıya girme puanları uygulama sonrasında anlamlı şekilde artış göstermiştir. Araştırmada okul öncesi eğitimde üç boyutlu çizim yazılımlarının öğretimi sürecinde bireyselleştirilmiş öğretim ve serbest proje etkinliklerinin etkili bir şekilde kullanılabileceği vurgulanmıştır.
\end{abstract}

Anahtar sözcükler: yaratıcılık, teknoloji, okul öncesi eğitim, teknoloji eğitimi

\section{Giriş}

Yaratıcılık kavramı lâtince "creare" sözcügünden gelmekte ve doğurmak, yaratmak, meydana getirmek anlamına gelmektedir (San ve Güleryüz, 2004). Torrence'a göre (1968) yaratıcılık bireyin bir problemin çözümünde yeni bir ürün ortaya koyma sürecidir (Akt. Erdoğdu, 2006). En yalın tanımı ile ise yaratıcılık hayal gücü yüksek yeni fikirlerin ortaya çıkması olarak tanımlanmaktadır (Miller, 1988). Günümüzde toplumların gelişen dünyada rekabet edebilmeleri için yaratıcı bireyler yetiştirmeleri gerekmektedir. Toplumların ayakta kalabilmesi ve refah seviyesini artırabilmesi için inovasyon yapabilmesi, inovasyon için ise yaratıcı bireylerin yetiştirilmesi gerekmektedir (Elçi, 2007; McLean, 2005). OECD (2008) raporuna göre de yaratıcı düşünme, eleştirel düşünme, problem çözme, iletişim, işbirliği yapabilme, girişimcilik, liderlik, enformasyon, medya ve iletişim teknolojilerini kullanabilme 21. yüzyıl çalışanlarının kazanması gereken beceriler arasında gösterilmiştir. $\mathrm{Bu}$ becerilerden yaratıcılık yeni bir fikir ve ürünün ortaya çıkması açısından en kritik beceridir. Ayrıca Kurtzberg (2005)'e göre de yaratıc1lı değişen iş dünyası için çalışan iş doyumu ve özgüveni açısından önemli bir pozitif güçtür (Tok ve Sevinç, 2012). Bu nedenle bireyin yaşamının ilk ve en kritik dönemlerini geçirdiği formal eğitim kurumlarındaki öğrenme yaşantıları onların yaratıcılıklarını destekleyici nitelikte olmalıdır. Özellikle de okul öncesi dönem yaratıcılı̆̆ın gelişmesinde ve desteklenmesinde çok önemli bir role sahiptir.

Yaratıcı düşünmenin en önemli belirleyici noktası hayal etmektir. Hayal gücü yüksek bireyler genellikle yaratıcı kişilerdir. Yaratıcı bireyler yeni ve özgün ürünler ortaya koymak için hayal gücünü kullanan (Öztürk, 2004), düşünceleri esnek, yeni

\footnotetext{
* Sorumlu Yazar: Doç.Dr., Akdeniz Üniversitesi, Antalya, serkansendag@akdeniz.edu.tr

** Ögretim Görevlisi Dr., Mehmet Akif Ersoy Üniversitesi, oerol@mehmetakif.edu.tr
} 
durumlara kolaylıkla uyum sağlayan, meraklı ve hırslı (San, 1996) kişilerdir. Aslında bireyler genellikle yaratıcı bir doğa ile meydana gelirler. Fakat bireyin bu özelliği yaş ilerledikçe bastırılarak gerileyebilir ya da geliştirilerek artabilir. Örneğin yedi yaşındaki bir çocuk \%75 yaratıcı iken kırk yaşındaki bir yetişkin \%2 yaratıcı özelliğe sahip olabilir (Eiffert, 1999). Okul öncesi dönemde çocukların hayal gücü oldukça yüksektir ve yaratıcı düşünme becerilerinin gelişmesi açısından kritik bir dönemdir. Okul öncesi eğitim dönemini kapsayan ilk altı yaş, çocuğun bedensel, bilişsel, dil, motor, sosyal ve duygusal gelişim alanlarının desteklendiği, öz bakım becerilerinin kazanıldığ 1 ve kişilik yapısının biçimlenmeye başladığı önemli bir dönemdir. Bu süreç içerisinde kazanılan davranış biçimleri, tüm yaşam boyunca devam etmektedir. $\mathrm{Bu}$ nedenle bu dönemin sağlıklı bir şekilde değerlendirilmesi yaratıcı bireyler yetiştirilmesi açısından önem taşımaktadır (Oktay, 1999; Ural ve Ramazan, 2007; Yavuzer, 2006; Y1ldız, Özkal ve Çetingöz, 2003). Eğer çocukların bu özellikleri desteklenmez ve geliştirilmez ise yaratıcı özellikleri zamanla körelebilmektedir. Alan yazın incelendiğinde, okul öncesi dönemde yaratıcılığı artırmada daha çok geleneksel yöntemler kullanıldı̆̆ görülmektedir. Örneğin dil etkinlikleri kapsamında öykü tamamlama, bir fotoğraf karesinden yola çıkarak öykü oluşturma, öykü canlandırma, yaratıcı drama ve oyun etkinlikleri, çocuğa orijinal düşünebilme ve bağımsız çalışabilme olanağını tanıyan sanatsal etkinlikler, kendini ifade etme ve imgelemeyi geliştirmede etkili olan görsel sanat etkinlikleri, kendine güven duygusunu geliştirici müzik etkinlikleri, çocukların çevrelerindeki olaylara duyarlı olmaları, olup bitenler hakkında fikir yürütmeleri, gözlem yapma alışkanlığı ve bu gözlemlerini eleştirerek yeni fikirler oluşturmalarını sağlayan fen ve matematik etkinlikleri yapılmaktadır (Argun, 2011; Can Yaşar, 2009; Can Yaşar ve Aral, 2010; Can Yaşar ve Aral, 2011; Ceylan, 2008; Oğuzkan, 1986; San, 1979; Şahintürk, 2012; ). Fakat eğitimin her kademesinde kullanılan bilgi ve iletişim teknolojileri de okul öncesi dönemde yaratıcılığ geliştirmede alternatif bir yol olarak kullanılabilir. Özellikle bazı yazılımların yaratıcılığı destekleyici ve geliştirici nitelikte kullanılabileceğine ilişkin literatürde çalışmalar bulunmaktadır (Karakaya ve Demirkan, 2015; Liveri, Xanthacoub ve Kailac, 2012; Zhou, Chen ve Lu, 2014). Bu kapsamda, teknoloji ve yaratıcılık arasındaki ilişkilerin araştırıldığı çalışmalar ele alındığında bilgi ve iletişim teknolojilerinin bilişsel araç olarak kullanıldığı çalışmalar ortaya çıkmaktadır (Charsky ve Ressler, 2011; Hwang, Chu, Lin ve Tsai, 2011; Koçoğlu ve Köymen, 2003; Robertson, Walther ve Radcliffe, 2007; Subh, 1999). Bilişsel araçlar ile ilgili çalışmaları ile bilinen Jonassen (1996) bilgi ve iletişim teknolojilerinin, özellikle de bilgisayarların bilişsel araç olarak kullanıldığ öğrenme çevrelerinde yaratıcılık gibi üst düzey düşünme becerilerin geliştiğini savunmaktadır (Akt. Koçoğlu ve Köymen, 2003). Bilişsel araçlar bireylerin düşük düzeyli bilişsel yükünü paylaşarak yüksek düzeyli düşünme becerilerini kullanmalarına olanak veren her türlü zihinsel ya da bilişsel bir aygıt olarak tanımlanmaktadır (Jonassen, 2000). Bilişsel araçlar, özellikle tasarım ve modelleme amaçlı kullanılan bilgisayar yazılımları, kullanıcılara sınırsız deneme yanılma, tasarım aşamasında bilişsel destek ve anında düzeltme olanağı tanıyarak yaratıcı ürünler ortaya çıkarmalarına yardımcı olmaktadır (Solomon, Perkins ve Globerson, 1991). Loveless (2002)'a göre de yaratıcılığı desteklemek amacıyla bilgi ve iletişim teknolojileri 
düşünceyi geliştirme, bağlantı kurma, yaratma ve anlam katma, işbirliği yapma ve iletişim kurma, yayınlama, sunma ve değerlendirme amaçlı kullanılabilmektedir. Özellikle yaratma ve anlam katma amaçlı kullanılan tasarım araçları düzenleme, manipüle etme ve yeniden düzenleme özellikleri ile bireylere üst düzey yaratıc1 çalışmalar yapma olanağı tanımaktadır (Atherton, 2002; Loveless, 2002).

Birçok bilgisayar yazılımının özellikle LOGO (Subh, 1999), Web tasarım araçları (Koçoğlu ve Köymen, 2003), CAD gibi bilgisayar destekli tasarım araçlarının (Robertson, Walther ve Radcliffe, 2007) yaratıcılığa etkisini inceleyen araştırmalar yapılmış ve birçok çalışma tasarım araçlarının yaratıcılığı geliştirdiğini ortaya koymuştur. SketchUp programı da bir tasarım aracı olarak yaratıcılığı geliştirme açısından ele elınmalıdır (Liveri, Xanthacoub ve Kailac, 2012).

1999 yılında Brad Schell tarafından geliştirilen ve 2006 yılından buyana Google tarafından kullanıcılara sunulan SketchUp programı kullanıcıların kolaylıkla üç boyutlu modeller oluşturabildiği, bu modeller üzerinde anında ve hızlı bir şekilde değişiklikler yapabildiği, bu değişiklikleri anında görebildiği ve bu modelleri paylaşabildiği bir tasarım aracıdır. Öğrenmesi ve kullanması diğer üç boyutlu tasarım araçlarına göre oldukça kolaydır. Basitleştirilmiş arayüzü, kullanımı kolay araç kutusu, yardımlı çizim sistemi ve akıllı menüleri ile kullanıcılara oldukça yardımcı olmaktadır. Yazılım kullanıcıların tasarım verimini yükseltmekte, tasarım işini kolaylaştırarak yaratıcı çizimler için zaman yaratmaktadır. Böylece kullanıcılar SketchUp tasarım aracını bir bilişsel araç gibi kullanarak yoğun zihinsel çaba gerektiren üç boyutlu tasarım sürecinde zaman harcamak yerine tasarımlarını daha yaratıcı hale getirmek için uğraşabilmektedirler (Han, 2011). Çünkü bu tarz yazılımlar kullanıcılara sınırsız deneme, her türlü değişikliği anında yapabilme ve hayal güçlerini sonuna kadar kullanabilme olanağı sağlamaktadır (Loveless, 2002; Sun, 2007). SketchUp programı bu noktada yaratıcılığı geliştirmek için kullanılabilir bir yazılım olabilir. Fakat bu aşamada okul öncesi dönemde çocukların bilgisayar kullanabilme yeterlilikleri ve okul öncesi dönem çocuklarına bilgisayar öğretimi sorunu ortaya çıkmaktadır. Çocukların bilgisayar ile hangi yaşta tanışması gerektiği ile ilgili farklı görüşler bulunmaktadır. Bazı araştırmacılara göre, çocuklar bilgisayarlar ile erken çocukluk dönemi olan okul öncesi dönemde tanışmalıdır. Çünkü bilgisayarlar çocukların zihinsel süreçlerini sürekli açık tutar, keşfederek ve eğlenerek öğrenmelerini sağlar, sınırsız deneme yanılma ve tekrar yapma olanağı ile kendi kendine öğrenme fursatı sunar, problem çözme becerilerini geliştirerek yaratıcılığını artırır (İnan, 2005; Yaşar, 2002). Ayrıca bu dönemde meraklı ve çevresindeki her şeyi keşfetmeye çalışan çocuklar bilgisayar gibi araçları kolaylıkla kullanmayı öğrenebilirler. Fakat bazı araştırmacılara göre de bilgisayarlar çocukları edilgen hale getirerek ve onları çevrelerinden soğutarak asosyal hale getirebilmektedir (Healy, 1998). Bilgisayarların çocukların gelişimine olumsuz yönleri olmasına rağmen genel kanı uygun zaman, ortam ve program seçildiğinde bilgisayarların çocukların bilişsel gelişimine katkıda bulunarak onların öğrenme süreçlerine, yaratıcılıklarına ve problem çözme becerilerine katkısının olduğu yönündedir (Haugland, 1992; Seniuk, 2001). Bu süreçte uygun program seçimi ve öğretim sürecinin çocuklara göre 
tasarlanması önemlidir. Okul öncesi dönem çocukları için uygun bilgisayar programı seçerken programların kolay kullanılabilir olmasına, çocuklar henüz okuma yazma becerilerine sahip olmadıkları için olduğunca az yazılı komut içeren, grafik yönü daha ağır, etkileşimi artıcı uyarıcılar içeren yazılımlar olmasına, çocukların keşfedici ve yaratıcı yönünü ön plana çıkaran, deneme yanılma olanağı tanıyan yazılımlar olmasına dikkat edilmelidir (Hohmann, 1998; Yaşar, 2002). SketchUp yazılımı kolay kullanılabilir yapısı, deneme yanılma ve tekrar edebilme özellikleri ile çocukların rahatlıkla öğrenip kullanabileceği bir yazılım olarak görünmektedir.

Okul öncesinde; öğrenme merkezlerinde, oyun etkinliklerinde ve sanat etkinliklerinde çocukların yaratıcılıklarını destekleyici nitelikte çalışmalar yapılmaktadır. Bu çalışmalar çocukların yaratıcılıklarını destekleme konusunda oldukça önemli etkinlikler olmakla birlikte mevcut materyallerle yapılan etkinlikler olduklarından çocukların hayal ettikleri her şeyi gerçekleştirmeleri her zaman olanaklı olamamaktadır (Argun, 2011). Çocuklar beş-altı yaşlarında bazen yaptıkları resimlerde ya da diğer öğrenme merkezlerindeki oyunlarında uzayı, farklı gezegenleri, masal diyarlarını ve kahramanlarını, sihir gibi dünya dışı olay ya da olguları sergilemeye çalışırlar (Malchiodi, 1998). Çoğu zaman da ortaya çıkardıkları ürün hayal ettiklerine benzememektedir. Çünkü gelişim özellikleri itibariyle, çocukların hayal ettiklerini bu materyalleri kullanarak yapabilmeleri mümkün olmamaktadır. Bu nedenle SketchUp yazılımı bu dezavantajı ortadan kaldırabilecek nitelikte bir yazılım olarak değerlendirilmektedir. Çünkü SketchUp yazılımı ile kullanıcılara sınırsız deneme, her türlü değişikliği anında yapabilme ve hayal güçlerini sonuna kadar kullanabilme olanağı sağlamaktadır (Loveless, 2002; Sun, 2007).

Bu kapsamda bu çalışmada bireyselleştirilmiş öğrenme yaklaşımı kullanılarak yedi haftalık bir eğitim süreci planlanmış ve bu süreç sonunda çocukların yazılımı kullanarak kendi özgün projelerini gerçekleştirmeleri sağlanmıştır. Öğretimin bireyselleştirilmesi öğrenenlerin ilgi ve gereksinimlerini, öğrenme hız ve yeteneklerini dikkate alarak öğrenme ve öğretme etkinliklerinin düzenlenmesidir (Hıal, 1989). Öğretimin bireyselleştirilmesi öğrenenlere kendi öğrenme hızlarında öğrenme firsatı sağladığı için öğrenenlerin motivasyonunu artırarak akademik başarılarının, problem çözme ve yaratıcılık becerilerinin gelişimine katkı sağlayabilir (Schargel ve Smink, 2001). Her bireyin bilgiyi yapılandırma biçimi farklılık gösterdiğinden dolayı bireysel öğrenmeyi destekleyici; probleme dayalı öğrenme, işbirliğine dayalı öğrenme, proje tabanlı öğrenme, rol oynama, benzeşim ve sorgulama yoluyla öğrenme gibi yöntem ve stratejiler kullanılabilir (Switzer, 2004). Bireyselleştirilmiş öğretimin uygulandığ eğitsel ortamda öğretmen ile öğrenci arasında yeni bir ilişki biçimi gelişir. Öğretmen öğrencilerinin bireysel farklılıklarını dikkate alarak öğrenci merkezli bir öğrenme planlar, her öğrencinin öğrenme hızı ve kapasitesine göre öğrenme ortamını ve materyalini düzenler, öğrencinin içinden çıkamadığı durumlarda öğrenciye rehberlik eder, öğrenmeyi kolaylaştırıcı danışmanlık yapar (Demirel, 2007). Öğretmen bu durumda sınıfta bilgi aktaran ve disiplin sağlayan mutlak bir otorite değil, öğrenmeyi kolaylaştırıcı bir danışmandır. Öğrenci de bilgiyi doğrudan ezberleyen pasif bir alıcı 
değil öğrenmenin merkezinde aktif, kendi öğrenme hızını ve kapasitesini bilen kendi öğrenme sürecini kontrol eden öğrenenlerdir.

Öğrenmeyi bireyselleştirme adına uygulanan yöntemlerden biri proje tabanlı öğrenmedir. Proje tabanlı öğrenme öğrencilerin öğrenmenin merkezinde kendi öğrenmelerini kurgulayıp yönlendirdikleri, süreç sonunda kendi ürünlerini ortaya koydukları, üst düzey düşünme becerilerini geliştiren öğrenme yaklaşımıdır (Cole, Means, Simkins ve Tavali, 2002; Erdem, 2002). Proje tabanlı öğrenme süreci bireysel olduğu kadar işbirliğine de dayanır. Ortaya çıkan ürün bir sunum ya da performans ya da tasarım olabilir. Süreç amacı, yöntemi ve hedefleri belirlenen proje etrafinda belirli bir zaman diliminde gerçekleşir. Öğrenci projeyi sonuca ulaştırana kadar kendi öğrenmesinden sorumludur. Bu çerçevede bu araştırma kapsamında okul öncesi altı yaş çocuklarının gelişim özellikleri de göz önünde bulundurularak öğretmenlerin her çocuğun kendi hızına göre ilerlemesine olanak tanıdığı bir yaklaşımla SketchUp yazılımının öğretimi yukarıda kuramsal çerçevesi verilen bireyselleştirilmiş öğretim yaklaşımı gerçekleştirilmiş; ardından çocukların bireysel proje etkinlikleri gerçekleştirmelerine rehberlik edilmiştir. Çocuklar her hafta teker teker bilgisayar başına alınarak programın öğretimi çocuğun kendi ilerleme hızı göz önünde bulundurularak öğretilmiş ve uygulama sonrasında çocuğun kendi özelliklerine uygun olarak alıştırma yapmasına olanak tanınmıştır. Uygulama sonunda çocukların kendi belirledikleri bir konuda proje yapmaları sağlanmıştır.

$\mathrm{Bu}$ bağlamda yaratıcılık potansiyelinin en üst düzeyde olduğu okul öncesi dönemde çocukların yaratıcılıklarının desteklenmesi önem kazanmaktadır. Ayrıca alan yazın incelendiğinde bilgi ve iletişim teknolojileri ve yaratıcılık arasındaki ilişkinin incelendiği çalışmaların (Crow, 2006; Erol ve Taş, 2012; Koçoğlu ve Köymen, 2003), okul öncesi dönem çocuklarında bilgisayar eğitimi ile ilgili çalışmaların (Çankaya, 2012; Demir, 2007; Kesicioğlu, 2011; Sancak, 2003) oldukça az olduğu görülmüştür. Bununla birlikte alan yazında okul öncesi dönem çocuklarının yaratıcılıklarını geliştirmek için geleneksel yöntemlerden farklı olarak bilgisayar tabanlı bilişsel araçlarla desteklendiği çalışmalara ise rastlanmamıştır. Bu bağlamda bu çalışmada alan yazındaki bu eksikliklere katkı sağlayabilmek için SketchUp yazılımının okul öncesi çocuklarının yaratıcılığını desteklemede bilişsel bir araç olarak kullanılıp kullanılamayacağı konusunda ön bilgi sağlamayı amaçlamaktadır. Bu amaca ulaşmak için aşağıdaki sorulara yanıt aranacaktır:

- Okul öncesi çocukların resim tabanlı Torrance Yaratıcılık ön testi ile son testi arasında anlamlı bir fark var mıdır?

- Okul öncesi çocukların SketchUp yazılımı ile etkileşimleri nasıldır?

- Okul öncesi çocukların projelerinin yaratıcılık alt boyutlarına göre düzeyleri nasildır?

\section{Yöntem}

$\mathrm{Bu}$ araştırma nicel bir çalışma olup nitel veriler ile desteklenmiştir. Araştırmada tek grup ön test son test deseni kullanılmıştır. Bu desende deneysel işlemin etkisi tek bir 
grup üzerinde yapılan çalışmayla test edilir. Deneklerin bağımlı değişkene ait ölçümleri uygulama öncesi ön test uygulama sonrası son test şeklindedir. Aynı deneklere aynı ölçme aracı kullanılır. Desende tek gruba ait ön test ve son test değerleri arasındaki farkın anlamlılığ̣ test edilir (Büyüköztürk, Çakmak, Akgün, Karadeniz ve Demirel, 2011). Fakat bu yöntem deneysel çalışmalarda iç geçerliliği düşürmektedir. Bundan dolayı bu durum çalışmanın sınırlılıkları arasında yer almaktadır. Araştırmanın deseni Tablo 1'de verilmiştir.

Tablo 1

Araştırma Deseni

\begin{tabular}{cccc}
\hline Gruplar & Öntest & İşlem & Sontest \\
\hline D & TYT & X SU & TYT \\
\hline
\end{tabular}

D: Deney Grubu

TYT: Torrence Yaratıcılık Testi

XSU: SketchUp Uygulaması (9 Hafta)

\section{Çalışma Grubu}

Araştırmaya bir devlet Anaokulu'nda altı yaş grubuna devam eden 23 çocuk katılmıştır. Çalışmada altı yaş grubu çocuklar, okul öncesi dönemde diğer yaş gruplarına göre motor ve bilişsel becerilerinin daha fazla gelişmiş olduğu varsayımı ile seçilmiştir. Çalışma kapsamında katılımcıların proje geliştirmeleri gerektiğinden tamamının evinde bilgisayar olduğu yapılan ön görüşme ile tespit edilerek örnekleme dâhil edilmişlerdir.

\section{Veri Toplama Araçları}

Araştırmada okul öncesi dönem çocuklarının yaratıcılık becerilerini ölçmek için Torrance (1966) tarafından geliştirilen ve Aslan (2001) tarafından Türk çocuklarına uyarlaması yapılan Torrance Yaratıcı Düşünme Testi Şekilsel A Formu kullanılmıştır. Şekilsel A formu resim oluşturma, resim tamamlama ve paralel çizgiler olmak üzere üç etkinlikten oluşmaktadır (Öncü, 2003; Torrance, 1973).

Resim oluşturma etkinliğinde tamamlanmamış bir şekil yer almaktadır. Bireyden bu şeklin etrafına ya da içine çizimler yaparak bir kompozisyon oluşturması istenir. Resim tamamlama etkinliğinde 10 tane tamamlanmamış figür yer almaktadır. Bireyden bu figürlere yeni çizgiler ekleyerek yeni obje ve resimler oluşturması istenir. Paralel çizgiler etkinliğinde ise otuz paralel çizgi yer almaktadır. Bireyin bu paralel çizgiler arasına, üzerine ya da dışına çizimler yaparak çeşitli kompozisyonlar oluşturulması amaçlanır. Tamamlanmış her bir figüre isim verilerek puanlama yapılır (Öncü, 2003).

Test yaratıcılığın akıcılık, esneklik, orijinallik ve ayrıntılılık alt boyutlarını ölçmektedir. Puanlama hesaplanırken bu dört alt boyut ayrı ayrı ve toplam puan olarak 
hesaplanmaktadır. Akıcılık; çok sayıda fikir ve çağrışım üretebilme, esneklik; aynı uyaranla ilgili değişik fikirler üretme ve birbirinden değişik yaklaşımlar kullanma, orijinallik; yeni, alışılmamış ve az rastlanan fikirler üretme ayrıntıya girme ise verilen yalın bir uyaranı ayrıntılı ve özenli bir biçimde işleyip geliştirme becerilerini içermektedir (Öncü, 2003; Torrance ve Goff, 1989).

Testin ilk Türkçe uyarlaması Aksu (1985) tarafından yapılmış ve testin geçerlilik ve güvenilirlik çalışması sonucunda her bir alt boyut için Pearson Momentler Çarpımı ile geçerlililk hesaplanmış, akıcılık için .6238; esneklik için .6848; özgünlük için .4276; ayrıntılılık için .3389; ve son olarak toplam test için .5800 olarak bulunmuştur. Ayrıca testin Aslan (2001) tarafından yapılan Türkçe uyarlama çalışmasında ise iç geçerlilik toplam şekilsel test için .56 olarak bulunmuştur.

Ayrıca araştırmada öğrencilerin SketchUp yazılımı ile etkileşimlerini değerlendirmek amacıyla araştırmacı notları ve video kayıtları tutulmuştur. Araştırmacı notları ve video kayıtları incelenerek raporlaştırılmıştır. Bunun yanı sıra çocukların gerçekleştirdikleri projeleri değerlendirmek üzere orijinallik, esneklik ve akıcılık alt boyutlarında üç dereceli bir puanlama anahtarı oluşturulmuştur (1=düşük; 2=orta; 3=yüksek). Uygulamanın sonunda çocuklara açık uçlu sorularla programı kullanıp kullanmadıkları ve ileride programdan nasıl yararlanabileceklerine ilişkin sorular sorularak veriler toplanmıştır. Geliştirilen puanlama anahtarı Torrance Yaratıcılık Testi Şekilsel A Formu'nda yer alan orijinallik, esneklik ve akıcılık alt boyutları dikkate alınarak hazırlanmıştır. Çocuk projeleri bu puanlama anahtarı kullanılarak araştırmacılar tarafından ayrı ayrı puanlanmıştır ve puanlayıcılar arasındaki uyum Kendal W Uyum Testi ile test edilmiştir.

\section{Verilerin Analizi}

Torrence Yaratıcılık Testi Şekilsel A Formu'na ait veriler analiz edilirken, test toplam puanı ve tüm alt boyutlara ait puanların normal dağılıma uygunluğu test edilmiştir. Çocukların yaratıcılıklarının ön test ve son test arasında farklılık gösterip göstermediğini test etmek için; normal dağılım gösteren alt boyutlarda (Akıcılık, Esneklik, Ayrıntıya Girme) ve ölçek toplam puanında İlişkili Örneklem t Testi, normal dağılım göstermeyen alt boyutta (Orjinallik) ise Wilcoxon İşaretli Sıralar Testi uygulanmıştır. Çocuk projelerinin yaratıcılık alt boyutlarına göre üçlü derecelendirme içeren rubrik kullanarak yapılan değerlendirme aşamasında ise her bir alt boyut için ortalama puanlar hesaplanmış ve ayrıca üçlü dereceye göre ayrı ayrı frekans değerleri hesaplanmıştır. Ortalama puanların orta dereceye ("2") göre istatistiksel olarak anlamlı şekilde farklılaşıp farklılaşmadığını test etmek için Tek Örneklem t Testi yapılmıştır. Etki büyüklüğ̈̈ hesaplanırken Eta kare (ๆ2) istatistik yöntemi kullanılmıştır. Etki büyüklüğü eğer .01 ve .06 arasında ise küçük bir etkiden, .14' ün üzerinde ise geniş yani büyük bir etkiden söz edilebilir (Büyüköztürk, 2009). Nicel verilerin analizinde SPSS paket programı kullanılmıştır ve tüm testler için anlamlılık düzeyi \%95 ( $\alpha=0.05)$ alınmıştır. 


\section{Uygulama Süreci}

Uygulamaya başlamadan önce araştıramaya katılan 23 çocuğa evlerinde ebeveynleri ile programı kullanmaları için SketchUp programının yer aldığı CD verilmiştir. Uygulama toplam yedi hafta sürmüştür. İlk hafta ve son hafta verilerin toplanması için ön test ve son testler uygulanmış, son hafta çocuklar ile görüşme yapılmıştır. Uygulama süresince araştırmacılar değerlendirilmek üzere günlük tutmuşlar, ayrıca tüm uygulama süreci video kamera ile kayıt altına alınmıştır. Uygulama süreci Şekil 1'deki gibi şemalaştırılmıştır.

Şekil 1. Uygulama Süreci

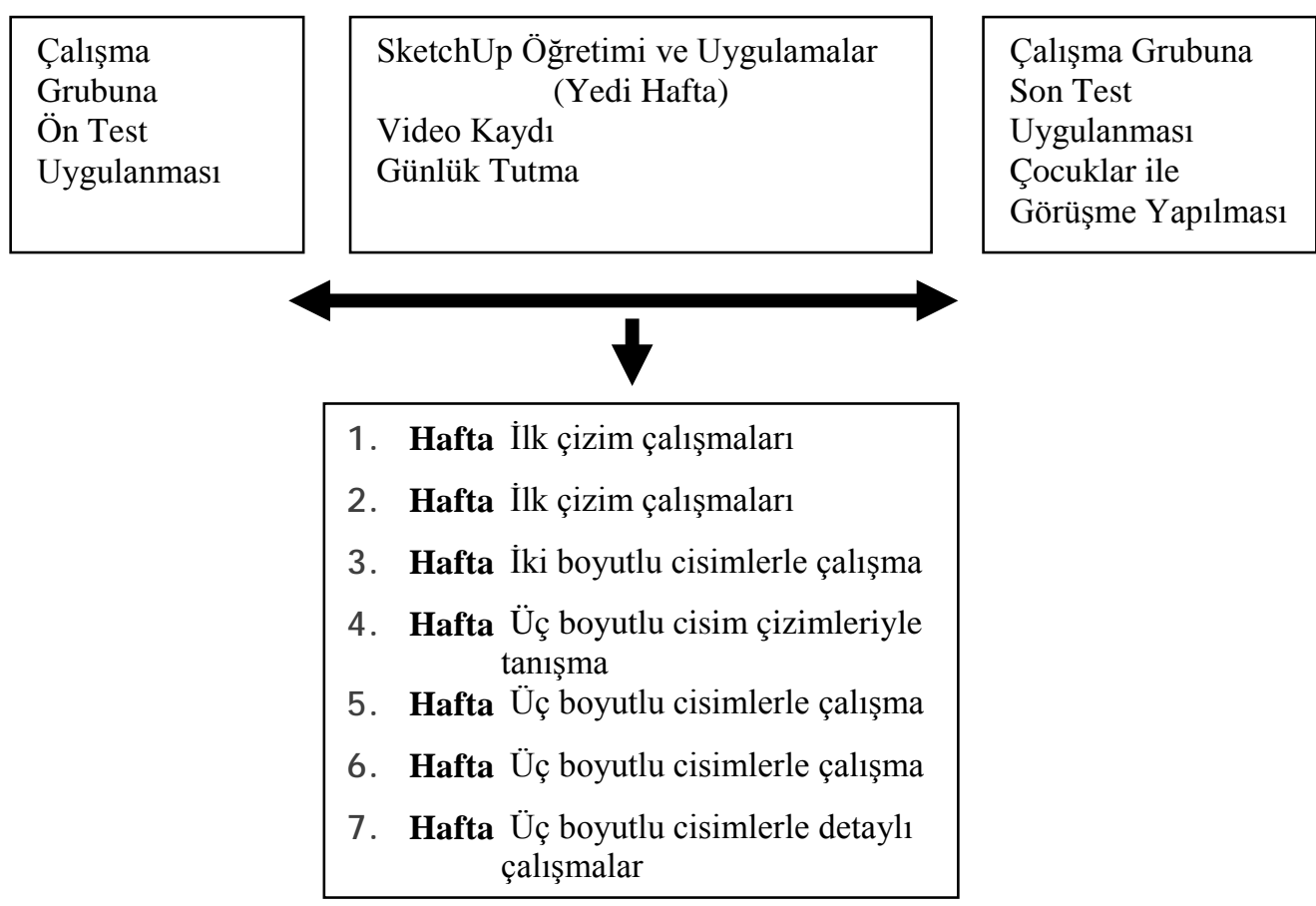

\section{Bulgular}

\section{Torrance Yaratıcılık Testi Şekilsel A Formu Ön Test- Son Test Sonuçları}

Tablo 2

Ön test-Son test Akıcılık Puanlarına Yönelik İlişkili Örneklem t-Testi Sonuçları

\begin{tabular}{ccccccc}
\hline Grup & $N$ & $\overline{\mathrm{x}}$ & ss & sd & $t$ & $p$ \\
\hline Ön test & 23 & 23.00 & 4.296 & 22 & 4.845 & .000 \\
Son test & 23 & 31.83 & 9.008 & 22 & & \\
\hline
\end{tabular}

Tablo 2'ye göre araştırmaya katılan çocukların Google SkethcUp eğitimi öncesindeki ön test akıcılık puanları ile Google SkethcUp eğitimi sonrasındaki son test 
akıcılık puanları arasındaki farkın [t(22)=4.845, $\mathrm{p}<.05]$ anlamlı olduğu belirlenmiştir. Ortalamalar incelendiğinde, uygulama öncesinde çocukların akıcılık toplam puanı ortalaması $\bar{x}=23.00$ iken, uygulama sonrası akıc1lk toplam puanı ortalamas1 $\bar{x}=31.83$ olduğu görülmektedir. Başka bir deyişle Google SketchUp eğitimi sonrasında çocukların akıcılık puanları anlamlı düzeyde artmıştır. Oluşan anlamlı farkın etki büyüklügü incelendiğinde $(\eta 2=.516)$ büyük ya da geniş bir etkiden bahsedilebilir.

Tablo 3

Ön test-Son test Toplam Esneklik Puanlarına Yönelik İlişkili Örneklem t-Testi Sonuçları

\begin{tabular}{ccccccc}
\hline Grup & $N$ & $\overline{\mathrm{x}}$ & ss & sd & $t$ & $p$ \\
\hline Ön test & 23 & 16.83 & 3.985 & 22 & \multirow{2}{*}{2.960} & .007 \\
Son test & 23 & 20.04 & 5.004 & 22 & & \\
\hline
\end{tabular}

Tablo 3'e göre araştırmaya katılan çocukların Google SkethcUp eğitimi öncesindeki ön test esneklik puanları ile Google SkethcUp eğitimi sonrasındaki son test esneklik puanları arasındaki farkın $\left[\mathrm{t}_{(22)}=2.96, \mathrm{p}<.05\right]$ anlamlı olduğu belirlenmiştir. Ortalamalar incelendiğinde, uygulama öncesinde çocukların esneklik toplam puanı ortalamsı $\overline{\mathrm{x}}=16.83$ iken, uygulama sonrası esneklik toplam puanı ortalamasının $\overline{\mathrm{x}}=20.04$ olduğu görülmektedir. Başka bir deyişle Google SkethcUp eğitimi sonrasında çocukların esneklik puanları anlamlı düzeyde artmıştır. Oluşan anlamlı farkın etki büyüklügü incelendiğinde $(\eta 2=.284)$ büyük ya da geniş bir etkiden bahsedilebilir.

Tablo 4

Ön test-Son test Toplam Ayrıntıya Girme Puanlarına Yönelik İlişkili Örneklem t-Testi Sonuçları

\begin{tabular}{ccccccc}
\hline Grup & $N$ & $\overline{\mathrm{x}}$ & ss & sd & $t$ & $p$ \\
\hline Ön test & 23 & 77.57 & 23.411 & 22 & \multirow{2}{*}{3.504} & .002 \\
Son test & 23 & 94.83 & 23.169 & 22 & & \\
\hline
\end{tabular}

Tablo 4'e göre araştırmaya katılan çocukların Google SkethcUp eğitimi öncesindeki ön test ayrıntıya girme puanları ile Google SkethcUp eğitimi sonrasındaki

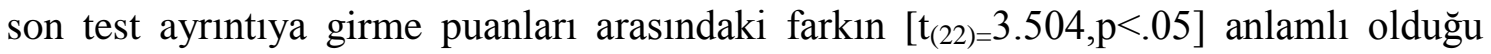
belirlenmiştir. Ortalamalar incelendiğinde, uygulama öncesinde çocukların ayrıntıya girme toplam puanı ortalaması $\overline{\mathrm{x}}=77.57$ iken, uygulama sonrası ayrıntıya girme toplam puanı ortalamasının $\overline{\mathrm{x}}=\mathbf{9 4 . 8 3}$ olduğu görülmektedir. Başka bir deyişle öğrenme merkezlerinde oyun etkinliklerinde, Google SkethcUp eğitimi sonrasında çocukların 
ayrıntıya girme puanları anlamlı düzeyde artmıştır. Oluşan anlamlı farkın etki büyüklüğü incelendiğinde ( $\eta 2=.350)$ büyük ya da geniş bir etkiden bahsedilebilir.

Tablo 5

Ön test-Son test Toplam Orijinallik Puanlarına Yönelik Wilcoxon Işaretli Siralar Testi Sonuçları

\begin{tabular}{cccccc}
\hline Ön test-Son test & $n$ & Sira Ortalamast & Sira Toplamlarl & $z$ & $p$ \\
\hline Negatif Sıra & 6 & 5.83 & 35.00 & & \\
Pozitif Sira & 17 & 14.18 & 241.00 & 3.134 & .002 \\
\hline
\end{tabular}

Tablo 5'e göre araştırmaya katılan çocukların Google SkethcUp eğitimi öncesindeki ön test orijinallik puanları ile Google SkethcUp eğitimi sonrasındaki son test orijinallik puaları arasındaki farkın $[z=2.05, p<.05]$ anlamlı olduğu belirlenmiştir. Fark puanlarının sıra ortalaması ve toplamları dikkate alındığında, gözlenen farkın pozitif sıralar yani son test orijinallik puanları lehine olduğu görülmektedir. Buna göre çocukların orijinallik puanları Google SketchUp eğitimi sonrasında anlamlı düzeyde artmıştır.

Tablo 6

Ön test-Son test Toplam Yaratıcıllk Puanlarına Yönelik İlişkili Örneklem t-Testi Sonuçları

\begin{tabular}{ccccccc}
\hline Grup & $N$ & $\overline{\mathrm{X}}$ & ss & sd & $t$ & $p$ \\
\hline Ön test & 23 & 153.26 & 35.037 & 22 & \multirow{2}{*}{0} \\
Son test & 23 & 194.70 & 48.441 & 22 & 4.43 & .000 \\
\hline
\end{tabular}

Tablo 6'ya göre araştırmaya katılan çocukların Google SkethcUp eğitimi öncesindeki ön test toplam yaratıcılık puanları ile Google SkethcUp eğitimi sonrasındaki son test toplam yaratıcılık puanları arasındaki farkın $[\mathrm{t}(22)=4.443, \mathrm{p}<.05]$ anlamlı olduğu belirlenmiştir. Ortalamalar incelendiğinde, uygulama öncesinde çocukların yaratıcılık toplam puanı ortalaması $\overline{\mathrm{x}}=153.26$ iken, uygulama sonrası yaratıcılık toplam puanı ortalamasının $\bar{x}=194.70$ olduğu görülmektedir. Başka bir deyişle Google SkethcUp eğitimi sonrasında çocukların toplam yaratıcılık puanları anlamlı düzeyde artmıştır. Oluşan anlamlı farkın etki büyüklüğü incelendiğinde ( $2=.470)$ büyük ya da geniş bir etkiden bahsedilebilir.

\section{Araştırmacı Günlükleri, Video Kayıtları ve Katılımcılara Ait Görüsşlerin Değerlendirilmesi}

Araştırmacı günlükleri ve video kaydı incelendiğinde, daha ilk haftadan çocukların programa karşı ilgilerinin yüksek olduğu, haftalar ilerledikçe çocukların 
bilgisayar kullanma ilgi ve becerilerinde gelişme olduğu ve uygulamalarda yapılan çalışmaların niteliğinde sürekli artış olduğu görülmüştür. Üç boyutlu çizimlerin yapıldığı 4. haftada çocukların ilk başta çizimleri yapmakta zorlandığı fakat gerek deneme yanılma yoluyla gerekse de SketchUp yazılımının sağladığı kullanım kolaylığı ile bu zorluğu bir hafta gibi bir sürede aştıkları görülmüştür. Ayrıca haftalar ilerledikçe çocukların SketchUp programına olan merakı daha da artmış, bilmedikleri birçok menü ve aracı sürekli eğitimcilere sormuşlar, hatta araçları denemekten kaçınmamışlardır. Çocukların çizimleri yaptıkça sevinç ve şaşkınlıklarını yansıttıkları, programı kullanmaya olan eğilimlerinin ve programı kullanmak için ayırdıkları zamanın arttı̆̆ görülmüştür. Eğitimin tamamlandığı 7. haftada çocukların eğitimin sürmesi yönünde istekli oldukları dikkat çekmiştir. Bunun yanı sıra eğitimin başında üçüncü boyutu anlamakta ve çizimlerine dahil etmekte zorlanan çocukların projelerinde üç boyutlu çizimlere yer vermeleri dikkat çekici bir konu olarak belirlenmiştir.

Eğitimden dört hafta sonra çocuklar ile yapılan görüşmede çocuklara programı halen kullanıp kullanmadıkları, programı kullanarak neler yaptıkları, ileride seçtikleri meslekte bu programı nasıl kullanabileceklerine ilişkin sorular sorulmuştur. Yapılan analiz sonucunda çocukların birçoğunun (\%57) programı halen kullandığı ve en çok ev, uçurtma, tren ve araba gibi nesneler ile at, kelebek gibi hayvanları ve çiçek çizdikleri ortaya çıkmıştır.

\section{Katılımcıların Projelerinin Değerlendirilmesi}

Araştırmaya dahil edilen çocukların uygulama sonunda SketchUp yazılımı kullanarak yaptıkları serbest bir proje çalışması özgünlük, esneklik ve akıcılık alt boyutlarına göre 3'lü ölçek kullanarak değerlendirilmiştir.

Tablo 7

Öğrenci Projelerinin Rubrik Değerlendirme Sonuçları

\begin{tabular}{cccccc}
\hline Alt Boyut & Derece & $f$ & $\%$ & $\overline{\mathrm{x}}$ & $p$ \\
\hline \multirow{2}{*}{ Özgünlük } & 1 & 7 & 30.434 & & \\
& 2 & 8 & 34.783 & 2.043 & .053 \\
& 3 & 8 & 34.783 & & \\
Esneklik & 1 & 2 & 8.695 & & \\
& 2 & 8 & 34.783 & 2.478 & .002 \\
& 3 & 13 & 56.521 & & \\
Akıc1lik & 1 & 2 & 8.695 & & \\
& 2 & 9 & 39.130 & 2.434 & .005 \\
& 3 & 12 & 52.173 & & \\
\hline
\end{tabular}


Çocukların yaptıkları projeler özgünlük alt boyutu açısından incelendiğinde; projelerin \%34.783'ünün $(n=8)$ üç puan ve \%34.783'ünün $(n=8)$ iki puan ve \%30.434'ünün $(n=7)$ bir puan aldığ1 görülmektedir. Projelerinin orijinallik açısından ortalaması $\overline{\mathrm{x}}=2.043$ 'tür ve orta derece olan iki puana göre istatistiksel açıdan anlamlı farklılık göstermemektedir. Yani projelerin orijinallik açısından orta düzeyde olduğu belirlenmiştir.

Çocukların yaptıkları projeler esneklik alt boyutu açısından incelendiğinde; projelerin \%56.521 inin $(n=13)$ üç puan ve \%34.783'ünün $(n=8)$ iki puan ve \%8.695'inin $(\mathrm{n}=2)$ bir puan aldığ görülmektedir. Projelerinin esneklik açısından ortalaması $\overline{\mathrm{x}}=2.478$ 'dir ve orta derece olan iki puana göre istatistiksel açıdan anlamlı farklılık göstermektedir. Yani projelerin esneklik açısından yüksek düzeyde olduğu belirlenmiştir.

Çocukların yaptıkları projeler akıcılık alt boyutu açısından incelendiğinde; projelerin \%52.173'ünün $(n=12)$ üç puan ve \%39.130'unun $(n=8)$ iki puan ve \%8.695'inin $(\mathrm{n}=2)$ bir puan aldığı görülmektedir. Projelerinin akıcılık açısından ortalaması $\overline{\mathrm{x}}=2.434$ 'tür ve orta derece olan iki puana göre istatistiksel açıdan anlamlı farklılık göstermektedir. Yani projelerin akıcılık açısından yüksek düzey olduğu söylenebilir.

\section{Sonuç ve Tartışma}

Okul öncesi altı yaş döneminde 3D çizim programlarının çocukların yaratıcılıklarını destekleyip destekleyemeyeceğine ilişkin sonuçları tartışmayı amaçlayan bu çalışma sonucunda gerçekleştirilen Bireselleştirilmiş Öğretim ve Proje Etkinlikleri ile işe koşulan Google SketchUp eğitiminin okul öncesi çocukların yaratıcılıklarını desteklemede etkili olabileceği yönünde bulgular elde edilmiştir. Çocukların uygulama sonunda yapılan yaratıcılık testi ölçümlerine göre hem toplam puanlarında hem de Akıcılık, Esneklik, Ayrıntıya Girme ve Orijinallik alt boyutlarında anlamlı düzeyde bir artış olduğu tespit edilmiştir. Araç bağlamında yapılan çalışmalar incelendiğinde bazı yazılımların yaratıcılığı desteklediği ve geliştirdiği görülmektedir (Karakaya ve Demirkan, 2015; Liveri, Zhou, Chen ve Lu, 2014). Farklı yaş grubuna ait bir çalışma olsa da; Xanthacoub ve Kailac (2012) lise öğrencileri ile yaptığ çalışmasında SketchUp programı ile yapılan tasarım etkinlikerinin yaratıcılığı artırdığı sonucunu bulmuştur. Bu bağlamda araştırma sonuçları yapılan araştırmanın sonuçları ile örtüşmektedir. Bununla birlikte bu araştırmada ortaya çıkan etkinin araştrıma desenin sınırlıklıkları göz önünde bulundurulduğunda daha ayrıntılı olarak araştırılması için tam deneysel modelde çalışmaların yapılmasına gereksinim vardır. Böyle bir etkinin ortaya çıkmasında Google SketchUp programının öğretiminde kullanılan bireyselleştirilmiş öğretim ve proje etkinliklerinin de yaratıcılığın desteklenmesinde olumlu bir etkisi olabileceği öngörülmektedir. Ayrıca bu sonuç; bireyselleştilimiş öğrenme ortamlarının öğrenenlerin motivasyonunu artırdığı, akademik başarılarını, problem çözme ve yaratıcılık becerilerini geliştirdiği ön görüsünü de desteklemektedir (Schargel ve Smink, 2001). Bu nedenle okul öncesi altı yaş çocukları ile uygulanan bu eğitimde 
yaratıcılığın desteklenmesinde sadece teknolojinin, teknoloji ile birlikte yöntemin nasıl bir etki meydana getirebileceğine ilişkin ayrıntılı deneysel çalışmaların yapılması önerilmektedir. $\mathrm{Bu}$ çalışmalardan elde edilecek sonuçların okul öncesi eğitimde bilgisayar kullanımına farklı bir boyut kazandırabileceği düşünülmektedir.

Okul öncesi dönem çocukları için uygun bilgisayar programı seçerken programların kolay kullanılabilir olmasına, çocuklar henüz okuma yazma becerilerine sahip olmadıkları için olduğunca az yazılı komut içeren, grafik yönü daha ağır, etkileşimi artıcı uyarıcılar içeren yazılımlar olmasına, çocukların keşfedici ve yaratıcı yönünü ön plana çıkaran, deneme yanılma olanağı tanıyan yazılımlar olmasına dikkat edilmelidir (Hohmann, 1998; Yaşar, 2002). Çalışmada kullanılan Google SketchUp yazılımının bu niteliklere sahip olduğu görülmektedir. Araştırma kapsamında elde edilen bulgular okul öncesi dönem altı yaş çocuklarının eğitim süresince Google SketchUp yazılımını kullanmaya karşı ilgili ve meraklı oldukları, bu ilgi ve merakın çocukların yazılımın farklı özelliklerini keşfetmeleri ile artarak devam ettiği ve yazılımın kullanımını öğrenmede zorlanmadıkları gözlenmiştir. Ayrıca eğitim tamamlandıktan sonra çocukların çoğunluğunun (\%57) dışarıdan hiçbir etki olmaksızın yazılımı kullanmaya devam ettikleri tespit edilmiştir. Bu tür yazılımların çocukları motive edici bu ve benzeri özelliklerinden yararlanılarak okul öncesi dönemde problem çözme ve tasarım yapma gibi üst düzey becerilerin geliştirilmesinde de işe koşulabilir.

Eğitimin ilk başlarında üç boyutlu nesnelerle çalışmakta zorlanan çocukların daha sonra üç boyutlu nesneleri kullanmaya başlamaları ve projelerinde üç boyutlu çizimlere yer vermeleri okul öncesi eğitimde kavramsal bilgi ve becerilerin geliştirilmesinde kullanılabileceğine ilişkin ipuçları sağlamaktadır. Ancak bu konuda da daha derinlemesine araştırmalar yapılması gerekmektedir. Bununla birlikte bu bulgular yapılan 7 haftalık öğretme-öğrenme etkinliklerinin çocukların SketchUp programına olan ilgi ve meraklarını yüksek tutabildiğini göstermektedir. Yüksek ilgi, merak ve motivasyon yine yaratıcılığ destekleyici özellikler olarak değerlendirilmektedir (İnan, 2005; San, 1996; Yaşar, 2002).

Katılımcıların Google SketchUp kullanarak yaptıkları projeler incelendiğinde; projelerin özgünlük açısından orta düzey, esneklik açısından ve akıcılık açısından yüksek düzeyde olduğu görülmektedir. Bir bilişsel araç olarak ele alındığında SketchUp programı çocukların yaratıcı ürünler ortaya çıkarmalarına (Solomon, Perkins ve Globerson, 1991) ve hayal güçlerini sonuna kadar kullanabilmelerine yardımcı olmuş olabilir. Bu sonuca göre bu bağlamda okul öncesi projelerde yaratıcılığın alt boyutlarından olan akıcılık ve esnekliğin desteklenmesinde bu çalışmada kullanılan yöntem ve stratejilerin etkili olabileceği öngörülmektedir. Bunun yanı sıra nesne ve kavramların genel geçer anlam ve ilişkiler dışında kullanılmasına yönelik becerileri ifade eden orijinallik alt boyutundaki becerilerin desteklenmesinde bu çalışma kapsamında kullanılamayan ve çocukların projelerini tasarlamaları aşamasında işe koşulabilecek "tabu sözcük ve kavramlar”, “rastgele girdi (random input)” gibi orijinalliği artırabilecek stratejiler kullanılabilir. 
Sonuç olarak bu araştırma kapsamında elde edilen bulgular, okul öncesi altı yaşta çocukların yaratıcılıklarını desteklemek amacıyla uygun yöntem ve stratejilerle birlikte SketchUp gibi üç boyutlu çizim yazılımlarından yararlanılabileceği sonucunu öne çıkartmaktadır. 


\section{Kaynakça}

Aksu, A. (1985). The effects method and sex on science achievement logical thinking ability of 5lh grade stıdents. Yayınlanmamış Yüksek Lisans Tezi, Orta Doğu Teknik Üniversitesi, Ankara.

Argun, Y. (2011). Okul öncesi dönemde yaratıcılık ve eğitimi. Ankara: Anı Yayıncılık.

Aslan, E. (2001). Torrance yaratıcı düşünce testi'nin Türkçe versiyonu. M.Ü. Atatürk Eğitim Fakültesi Ĕgitim Bilimleri Dergisi, 14, 19-40.

Atherton, T. (2002). Developing ideas with multimedia in the primary classroom. In Loveless, A.M. \& Dore, B. (eds), ICT in the primary classroom. Buckingham: Open University Press.

Büyüköztürk, Ş. (2009). Sosyal bilimler için veri analizi el kitabı. Ankara: Pegem Akademi.

Büyüköztürk, Ş., Çakmak, K. E., Akgün, Ö. E., Karadeniz, Ş. ve Demirel, F. (2009). Bilimsel araştırma yöntemleri. Ankara: Pegem Akdemi.

Can Yaşar, M. (2009). Anasınıfina devam eden altı yaş çocuklarının yaratıcı düşünme becerilerine drama ĕgitiminin etkisinin incelenmesi. Yayımlanmamış Doktora Tezi, Ankara Üniversitesi, Ankara.

Can Yaşar, M. ve Aral, N. (2010). Yaratıcı düşünme becerilerinde okul öncesi eğitimin etkisi. Kuramsal Ĕ̈itimbilim, 3(2), 201-209.

Can Yaşar, M. ve Aral, N. (2011). Altı yaş çocuklarının yaratıcı düşünme becerilerine sosyo-ekonomik düzey ve anne baba öğrenim düzeyinin etkisinin incelenmesi. Kuramsal Eğitimbilim, 4(1), 137-145.

Ceylan, E. (2008). Okul öncesi eğitime devam eden 5-6 yaş çocuklarının bilişsel tempoya göre yaratıcılık düzeylerinin incelenmesi. Yayınlanmamış Yükseklisans Tezi, Selçuk Üniversitesi, Konya.

Charsky, D. \& Ressler, W. (2011). Games are made for fun: Lessons on the effects of concept maps in the classroom use of computer games. Computers \& Education, 56(3), 604-615.

Cole, K., Means, B., Simkins, M. Tavali, F. (2002). Increasing student learning through multimedia projects. Virginia, Alexandria (USA): Association for Supervision and Curriculum Development.

Crow, B. (2006). Musical creativity and the new technology. Music Education Research, 8(1), 121 -130.

Çankaya, Ö. (2012). Bilgisayar oyunlarının okul öncesi eğitiminde kullanılmasının bazı matematiksel kavramların ögretimi üzerine etkisi. Yayınlanmamış Yükseklisans Tezi, Atatürk Üniversitesi, Erzurum.

Demir, N. (2007). Okul öncesi öğrencilerine renk kavramının kazandırılmasında bilgisayar destekli ve geleneksel öğretim yöntemlerinin karşılaştırılması. Yayınlanmamış Yükseklisans Tezi, Selçuk Üniversitesi, Konya. 
Demirel, Ö. (2007). Kuramdan uygulamaya ĕgitimde program geliştirme. Ankara: Pegema Akademi.

Eiffert, S.D. (1999). Cross-train your brain. Newyork: Amscom.

Elçi, Ş. (2007). Inovasyon kalkınmanın ve rekabetin anahtarı. Ankara: Technopolis Group.

Erdem, M. (2002). Proje tabanlı öğrenme. Hacettepe Üniversitesi Eğitim Fakültesi Dergisi, 22, 172-179.

Erdoğdu, Y. (2006). Yaratıcılık değerlendirme ölçeğinin türk kültürüne uyarlanması. İnönü Üniversitesi Eğitim Fakültesi Dergisi, 7(12), 61-79.

Erol, O. ve Taş, S. (2012). MYO öğrencilerinin bilgi ve iletişim teknolojilerini kullanma sıklıkları ile yaratıcılık algıları arasındaki ilişkinin incelenmesi. Mehmet Akif Ersoy Üniversitesi Sosyal Bilimler Enstitüsü Dergisi, 4(7), 82-104.

Han, L. (2011). Design and creativity in the digitized world. The International Journal of Learning, 17(10), 291-298.

Haugland, S.W. (1992). The effects of computer software on preschool children's developmental gains. Journal of Computing in Childhood Education, 3(1), 15- 30.

Hwang, G.J., Chu, H.C., Lin, Y.S. \& Tsai, C.C. (2011). A knowledge acquisition approach to developing Mindtools for organizing and sharing differentiating knowledge in a ubiquitous learning environment. Computers \& Education, 57(1), 1368-1377

Healy, J.M. (1998). Bağlantı doğru mu? Bilgisayarlar çocuklarımızın zihnini olumlu ve olumsuz yönde nasıl etkiliyor? Ahmet Gürsel (Çev.). İstanbul: Boyner Holding Yayınları.

Hızal, A. (1989). Ulusal eğitimin amacı ve bu amacı gerçekleştirmede okulun yeri. Anadolu Üniversitesi Eğitim Fakültesi Dergisi, 2(2), 119-123.

Hohmann, C. (1998). Evaluating and selecting software for children. Child Care Information Change, 60 -62.

İnan, N.U. (2005). Okul öncesinde bilgisayar kullanımı. In Sevinç, M. (Ed.) Erken çocuklukta gelişim ve eğitimde yeni yaklaşımlar. İstanbul: Morpa Kültür Yayınları.

Jonassen, D.H. (1996). Computers in the classroom: Mindtools for critical thinking. Columbus, OH: Merrill/Prentice-Hall.

Jonassen, D.H. (2000). Mindtools for engaging critical thinking in the classroom. $\mathrm{OH}$ : Prentice-Hall.

Karakaya A.F. ve Demirkan H. (2015). Collaborative digital environments to enhance the creativity of designers. Computers in Human Behavior, 42, 176-186.

Kesicioğlu, O.S. (2011). Doğrudan öğretim yöntemiyle hazırlanan ĕgitim programının ve bu yönteme göre hazırlanan bilgisayar destekli ĕ̆itim programının okul öncesi çocuklarının geometrik şekil kavramlarını öğrenmelerine etkisinin incelenmes. Yayınlanmamış Doktora Tezi, Gazi Üniversitesi, Ankara. 
Koçoğlu, Ç. ve Köymen, Ü. (2003). Öğrencilerin hiperortam tasarımcısı olarak katıldığ1 öğrenme çevresinin yaratıcı düşünmeye etkisi. Turkish Online Journal of Educational Technology-TOJET, 2(3), 127-136.

Kurtzberg, T.R. (2005). Feeling creative, being creative: An empirical study of diversity and creativity in teams. Creativity Research Journal, 17(1), 51-65.

Liveri, A., Xanthacoub, Y. \& Kailac, M. (2012). The Google Sketchup software as a tool to promote creativity in education in Greece. Procedia - Social and Behavioral Sciences, 69,1110 - 1117.

Loveless, A.M. (2002). Literature review in creativity, new technologies, and learning. $\begin{array}{llll}\text { Futurelab Arcive. } & \text { Retrieved } & 10.04 .2010 & \text { from }\end{array}$ http://www.nestafuturelab.org/research/reviews/cr01.htm.

Malchiodi, C.A. (1998). Çocukların resimlerini anlamak. İstanbul: Epsilon Yayınları.

McLean, L.D. (2005). Organizational culture's influence on creativity and innovation: A review of the literature and implications for human resource development. Advances in Developing Human Resources, 7(2), 226-246.

Miller, W.C. (1988). The creative edge, reading. Massachusetts: Addison-Wesley Publishing Company.

OECD, (2008). Germany workshop on "Advancing innovation: Human resources, education and training”. OECD Report. Retrieved 24.09.2012 from http://www.oecd.org.

Oğuzkan, S. (1986). Okul öncesi dönemde dramatik etkinlikler. YA-PA 4. Okul Öncesi Eğitimi ve Yaygınlaştırılması Semineri. İstanbul: YA-PA Yayınları.

Oktay, A. (1999). Okul öncesi eğitim ve temel ilkeleri. Marmara Üniversitesi Anaokulu/Anasınıfı Öğretmeni El Kitabı. İstanbul: YA-PA Yayınları.

Öncü, T. (2003). Torrance yaratıcı düşünme testleri-şekil testi aracılığıyla 12-14 yaşları arasındaki çocukların yaratıcılık düzeylerinin yaş ve cinsiyete göre karşılaştırılması. Ankara Üniversitesi Dil ve Tarih Coğrafya Fakültesi Dergisi, 43(1), 221-237

Öztürk, S. (2004). Eğitimde yaratıcı düşünme. Ondokuz Mayıs Üniversitesi Eğitim Fakültesi Dergisi, 18, 77-84.

Robertson, B.F., Walther, J., \& Radcliffe, D.F. (2007). Creativity and the use of CAD tools: Lessons for engineering design education from industry. Journal of Mechanical Design, 129(7), 753.

San, İ. (1979). Sanatsal yaratma ve çocukta yaratıcılık. Ankara: Türkiye İş Bankası Kültür Yayınları.

San, İ. (1996). Yaratıcı eğitim için yenilikler. Eğitimimize Bakışlar-I. İstanbul: Kültür Koleji Eğitim Vakfı Yayınları I.

San, İ. ve Güleryüz, H. (2004). Yaratıcı eğitim ve çoklu zeka uygulamaları. Ankara: Artım Yayınları.

Sancak, Ö. (2003). Okul öncesi eğitim kurumlarına devam eden 6 yaş çocuklarına sayı ve şekil kavramlarının kazandırılmasında bilgisayar destekli ĕgitim ile geleneksel 
eğitim yöntemlerinin karşılaştırılması. Yayımlanmamış Yükseklisans Tezi, Gazi Üniversitesi, Ankara.

Schargel, F.P. ve Smink, J. (2001). Strategies to help solve our school dropout problem. Larchmont, NY: Eye on Education.

Seniuk, C. (2001). Effects of computers on pre-school aged children, Calgary University at http://www.ucalgary.ca/ dabrent/380/webproj/cms.html.

Salomon, G., Perkins, D.N. \& Globerson, T. (1991). Partners in cognition: extending human intelligence with intelligent technologies. Educational Researcher, 20, 2-9.

Switzer, D. (2004). Individualized instruction. Smink, J. ve F.P. Schargel (Eds.), In Students graduate: A strategic approach to dropout prevention. (pp. 225-233). Larchmont, NY: Eye on Education.

Subh, T. (1999). The impact of LOGO on gifted children's achievement and creativity. Journal of Computer Assisted Learning, 15(2), 98-108.

Sun, L. (2007). Foster the development of computer-supported graphic design expertise through learning: Design knowledge, creativity and design management skills. Doktora Tezi, New York Üniversitesi, New York.

Şahintürk, Ö. (2012). Montessori yönteminin okul öncesi dönemde ögrrencilerin yaratıcı düşünmelerine etkisi. Yayınlanmamış Yükseklisans Tezi, Zonguldak Karaelmas Üniversitesi, Zonguldak.

Tok, E. ve Sevinç, M. (2012). Düşünme becerileri eğitiminin okul öncesi öğretmen adaylarının yaratıcı düşünme becerilerine etkisi. Eğitim ve Bilim, 37(164), 204-222.

Torrance, E.P. (1966). Torrance test of creative thinking. Technical manual. Personnel Press Inc. Princeton.

Torrance, E.P. (1968). Education and the creative potential. Minneapolis: The University of Minnesota Press.

Torrance, E.P. (1973). Torrance tests of creative thinking : Norms technical manual. Personnel Press Inc.: LM.

Torrance, E.P. ve Goff, K. (1989). A quiet revolution. Journal of Creative Behavior 23(2), 136-145.

Ural, O. ve Ramazan, O. (2007). Türkiye’de okul öncesi eğitimin dünü ve bugünü. Türkiye'de okul öncesi eğitim ve ilkögrretim sistemi temel sorunlar ve çözüm önerileri. Ankara: Türk Eğitim Derneği Yayınları.

Yaşar, Ş. (2002). Okul öncesi eğitimde bilgisayarın yeri ve önemi. Namlu, G. A. (Ed.) Okul öncesinde bilgisayar ögretimi. Eskişeir: Anadolu Yayınları.

Yavuzer H. (2006). Çocuk eğitimi el kitabı. İstanbul: Remzi Kitabevi.

Yıldız, V., Özkal, N. ve Çetingöz, D. (2003). Okul öncesi eğitimi alan ve almayan 7-8 yaş grubu çocuklarda yaratıcı potansiyelin değerlendirilmesi. Eğitim Araştırmaları Dergisi, 4(13), 129-137. 
Zhou, C., Chen, H., \& Lu, L. (2014). Students' perceptions of creativity in learning information technology (IT) in project groups. Computers in Human Behavior, 41, 454-463. 